\title{
Virtual slides: application in pulmonary pathology consultations
}

\author{
Janina Słodkowska ${ }^{1}$, Lech Chyczewski ${ }^{2}$, Michał Wojciechowski ${ }^{3}$ \\ ${ }^{1}$ Department of Telepathology, Institute of Tuberculosis and Lung Diseases, Warsaw, Poland \\ 2Department of Clinical Molecular Biology, Medical Academy of Białystok, Poland \\ ${ }^{3}$ Precoptic Co. Nikon Microscopes Distributor, Warsaw, Poland
}

\begin{abstract}
The Virtual Slide (VS) is an interactive microscope emulator that presents a complete digitized tissue section via the Internet. A successful implementation of VS has been observed for educational, research venues and quality control. VS acquisition for consultative pathology is not so common. The purpose of this study was to explore the efficacy and usability of VS in the consultative pulmonary telepathology. 20 lung tumors entered the study. The performance was programmed for 2 medical centers specialized in pulmonary pathology (beginner and advancer in telepathology). A high-quality VSs were prepared by Coolscope (Nikon, Eclipsnet VSL, Japan), and were evaluated via the Internet. The cases were reviewed for the second time with conventional light microscope. VS diagnostic accuracy and the interobserver variability were evaluated. Also the time taken by examiners to render the diagnoses and time needed to scan the microscopic slide were analyzed. Percentage concordance between original glass-slides diagnosis and diagnosis for VSs was very high. Pathologists found the download speed of VSs adequate; experience in telepathology reduced the time of VS diagnosis. VS implementation suggests advantages for teleconsulation and education but also indicate some technical limitations. This is the first Polish trial of VS implementation in telepathology consultative service.
\end{abstract}

Key words: Virtual Slide - Telepathology - Teleconsultation - Pulmonary oncology - Coolscope

\section{Introduction}

The development of rapid high resolution slide scanning technology and associated software for Virtual Microscopy across network is radically altering the way we perceive diagnostic pathology and is providing opportunities never before available in this discipline [1-10]. Virtual Microscopy refers to the high resolution digital scanning of entire glass slides and the generation of a digital Virtual Slide (VS) of the sample which can be viewed on-line. Having possessed a few years experience in telepathology (TP) consultations in the form of a still image transfer and interactive TP, in thoracic and pulmonary pathology, we have been looking a new TP method to be used in for daily routine histopathology. Our previous experience in telepathology consultations relied on two systems Samba 2005 (Samba Technologies, France) used for

Correspondence: J. Słodkowska, Dept. of Telepathology, National Research Institute of Tuberculosis and Lung Diseases, Płocka Str. 26, 01-138 Warsaw, Poland; tel.: (+4822) 4312 256, fax.: (+4822) 4312452, e-mail: i.slodkowska@gruz.igichp.edu.pl static telepathology and recently Coolscope (Nikon, Japan) [11-14]. Coolscope (Cs) is a fully automated system for digital histology that renders 3 TP methods: Large Image, Virtual Slide and interactive TP by web HTTP via the Internet. Our former results have shown that the interactive TP by Coolscope was more satisfactory and suitable for the routine pulmonary pathology teleconsultation than the Large Image method [13]. The trial using the Virtual Slide method for teleconsultations has been performed in the present study. True TP consultation by this method becomes used in medical practice for the first time in Poland.

The purpose of this study was to evaluate a new digitized technology of the VS method - the efficacy and usability for the teleconsultation of pulmonary oncology cases.

\section{Materials and methods}

Twenty cases (resection or surgical biopsy specimens) of the lung tumors (material of the Department of Clinical Molecular Biology, Medical University of Bialystok and the Department of Telepathology, I.TB.L.D. in Warsaw) entered the study. The cases of various diagnostic difficulties were included. The performance was pro- 
grammed for two medical centers (Warsaw and Bialystok) specialized in pulmonary pathology. Slides were scanned automatically using Coolscope (Nikon, EclipseNet VSL, Japan) by the use of $4 \times$ and $10 \times$ lens (N.A. 0.25). In case of cell-level diagnosis the $20 \times$ and $40 \times$ objectives (N.A. 0.65 ) were employed. A few microscopic slides required for scanning an additional autofocusing (AF): every microscopic field (AF1) - case 8; every third microscopic field (AF3) - case 9 and 13 or every fifth microscopic field (AF5) - case 1. The VSs were stored on local network Windows server and were examined via the Internet by two experienced pathologists: beginner [A] and advancer [B] in telepathology. Some cases have been discussed in personal conversation as well. The cases were reviewed for the second time with the conventional light microscope to perform a comparative analysis with VS diagnoses.

\section{Results}

29 VSs from 20 cases were assessed. Whole part slide consultations (although not all slides in entire case) included $\mathrm{H}+\mathrm{E}$ stained slides, immunostained with antibodies against AE1/AE3, S100, EMA, HMB45, chromogranin, synaptophysin, and slides of special staining in some cases. The experience has been classified for technical and human factors as follows: efficiency and quality of scanning, access of stored VS via internet, speed and user-friendliness of evaluation, easiness of consensus diagnoses.

The data summarizing the process of VS building are presented in Table 1 . The majority of glass slides were scanned with objective $10 \times$ and viewed with $10 \times$ and $20 \times$ magnification. The scanning time of the histological slides took from 4'30" to $1 \mathrm{hr} \mathrm{18'}$ and created a digital slide requiring from 45 up to $493 \mathrm{MB}$ hard disk space. The VS files exceeded more than $5 \mathrm{~GB}$ and needed to be operated on an advanced PC. Method used composed JPEG 2000 standard files, accessible for both teleconsultant workstations via the internet $(100 \mathrm{Mb} / \mathrm{sec})$. The VS were examined on the standard LCD monitors: Philips 170S and Belinea 101735 both of $1280 \times 1024$ pixels resolution. Time of VS uploading ranged between $5 "-15 "$. The mean time spent for one VS examination ranged from 5 to 25 minutes depending on the case. The time expended for VS diagnosis by teleconsultant A was longer approximately 2 times than the time used up by the teleconsultant B. For each case diagnostic questions regarding handling and image quality had to be answered. The image quality was dependent on the glass slide quality and the scanning procedure (used objective magnification and autofocusing). The scanning magnification using of $10 \times$ lens was not sufficient to obtain cell level diagnosis in two cases.

The spectrum of VS diagnoses prepared by both teleconsultants is demonstrated in Table 1. In 17 out of 20 cases $(85 \%)$ there was a full concordance between VS diagnoses prepared by both teleconsultants. The reasons for discordance were: insufficient image quality and incomplete panel of immunostaining (case 18), an unsatisfactory sample (case 12), or interpretation difference (case 11). The controversial cases were referred for additional immunostaining and for a panel discussion of the pathologists. Pathologists feel comfortable diagnosing VS using the Internet connection. The results obtained in 20 cases of VS are similar to those obtained in traditional second-opinion rounds. The turnaround time for remote diagnosis was on average $10^{\prime}(\mathrm{B})$ and $17^{\prime}(\mathrm{A})$.

\section{Discussion}

Virtual Microscopy provides a new medium for communication in human pathology. The application of Virtual Microscopy includes archives, teaching, continuous education exchange of rare cases, second opinion, and even conventional routine pathology. The Virtual Microscopy is particularly important in teleconsultations where pathologists no longer need to be restricted by the limitations of glass slides, geographic location or sending digital "snapshots" of tissue [1]. "The Virtual Microscope" has been implemented as a system in routine pathology or for distance education in some medical centers $[2,3,5,6,9,14-16]$.

The system Coolscope has been accepted by some professional groups around the world. Among several fields of applications, the Coolscope was applied for pulmonary pathology teleconsulation and for distance education $[12,13]$. In our present study, we found telereporting of a complete case possible in significant majority of cases providing VS diagnoses including judgment of remote consultants on tumor grade, immunohistochemical status and multiplicity of mixed tumors with diagnostic value. The turnaround time for remote diagnosis was on average 13'. The VS files were in medium volume range up to $493 \mathrm{MB}$. We reduced the file volume and the time of scanning by choosing the objective $10 \times$ for the VS creation in majority of VS. However in a few cases it was necessary to obtain the cell level of VS with the objective $20 \times$ or $40 \times$. The total VS database exceeded 5 GB and required to operate on the advanced $\mathrm{PC}$. The selection of the glass slides should be made to avoid additional autofocusing in the scanning procedure of uneven slides. The overall concordance of VS diagnoses was $85 \%$. Discordance or diagnostic doubts in VS evaluation also were referred to the optical microscopy diagnoses. Consequently, the discordance in $15 \%$ of VS diagnoses were not dependent on used method but resulted from the poor quality of tissue sample or insufficient immunostaining among selected cases.

The digital slide and the virtual microscopy can be alternative techniques in teleconsultation services. Major advantages of VS from the pathologist's perspective include efficiency and accessibility. In terms of efficiency, all the slides are accessible in focus, and 
Table 1. The summary of the VS building parameters and the teleconsultants diagnoses.

\begin{tabular}{|c|c|c|c|c|c|c|c|}
\hline & \multicolumn{2}{|c|}{ Patient } & \multirow{2}{*}{$\begin{array}{l}\text { Scan objective } \\
\text { autofocus }\end{array}$} & \multirow{2}{*}{$\begin{array}{l}\text { Time of } \\
\text { scanning }\end{array}$} & \multirow{2}{*}{$\begin{array}{l}\text { VS files } \\
(\mathrm{MB})\end{array}$} & \multirow{2}{*}{ VS diagnosis by teleconsultatnt $\mathrm{A}$} & \multirow{2}{*}{ VS diagnosis by teleconsultatnt $B$} \\
\hline & Sex & Age & & & & & \\
\hline 1 & $\mathrm{~F}$ & 45 & $10 \mathrm{x}, \mathrm{AF} 5$ & $7^{\prime}$ & 70 & Tumourlet & Tumourlet \\
\hline 2 & M & 55 & $10 \mathrm{x}$ & $\begin{array}{l}32^{\prime} \\
27^{\prime}\end{array}$ & $\begin{array}{l}199 \\
211\end{array}$ & $\begin{array}{l}\text { AD with NEd } \\
\text { Gl and G3 }\end{array}$ & $\begin{array}{l}\text { AD with Ned } \\
\text { Gl and G3 }\end{array}$ \\
\hline 3 & M & 52 & $10 \mathrm{x}$ & $23^{\prime}$ & 259 & Fetal AD with NEd & Fetal AD with NEd \\
\hline 4 & M & 26 & $10 \mathrm{x}$ & $20^{\prime}$ & 149 & PNET & PNET \\
\hline 5 & $\mathrm{~F}$ & 67 & $10 \mathrm{x}$ & $15^{\prime}$ & 165 & Wegener's granulomatosis & Wegener's granulomatosis \\
\hline 6 & M & 56 & $10 \mathrm{x}$ & $33^{\prime}$ & 287 & Hyalinizing granuloma & Hyalinizing granuloma \\
\hline 7 & M & 72 & $\begin{array}{c}4 \times \mathrm{AF} \\
4 \mathrm{x}\end{array}$ & $\begin{array}{l}41^{\prime} \\
10^{\prime}\end{array}$ & $\begin{array}{l}94 \\
81\end{array}$ & Nodular amyloid & Nodular amyloid \\
\hline 8 & $\mathrm{~F}$ & 32 & $4 \times \mathrm{AF} 1$ & $32^{\prime}$ & 84 & Granulomatosis bronchocentric & Granulomatosis bronchocentric \\
\hline 9 & M & 52 & $10 \times \mathrm{AF} 3$ & $20^{\prime}$ & 153 & Carcinoid atypical & Carcinoid atypical \\
\hline 10 & M & 71 & $10 \mathrm{x}$ & $\begin{array}{c}11^{\prime} \\
\mathrm{T}\end{array}$ & $\begin{array}{c}109 \\
79\end{array}$ & DINH & DINH \\
\hline 11 & $\mathrm{~F}$ & 55 & $10 \mathrm{x} A F$ & $\begin{array}{c}8^{\prime} \\
17^{\prime}\end{array}$ & $\begin{array}{l}89 \\
91\end{array}$ & Carcinoid atypical? & Sąuamous cell ca with NEd? \\
\hline 12 & M & 63 & $40 \times \mathrm{AF}$ & $22^{\prime}$ & 136 & Carcinoid?/SSC? & Carcinoid?/SSC? \\
\hline 13 & $\mathrm{M}$ & 40 & $20 \times A F 3$ & lh $18^{\prime}$ & 285 & Haemangioendothelioma? & Haemangioendothelioma? \\
\hline 14 & M & 52 & $10 \mathrm{x}$ & $15^{\prime}$ & 151 & Tumourlet & Tumourlet \\
\hline 15 & M & 54 & $10 \mathrm{x}$ & $\begin{array}{c}33^{\prime} \\
12^{\prime} \\
13^{\prime} \\
9^{\prime} \\
6^{\prime}\end{array}$ & $\begin{array}{c}407 \\
138 \\
134 \\
87 \\
61\end{array}$ & $\begin{array}{l}\text { Metastatic renal } \\
\text { cell carcinoma }\end{array}$ & $\begin{array}{l}\text { Metastatic renal } \\
\text { cell carcinoma }\end{array}$ \\
\hline 16 & $\mathrm{~F}$ & 10 & $10 \mathrm{x}$ & $22^{\prime}$ & 271 & Inflammatory myofibroblastic tu & Inflammatory myofibroblastic tu \\
\hline 17 & M & 45 & $20 x$ & $40^{\prime}$ & 701 & Mixed thymoma & Mixed thymoma \\
\hline 18 & $\mathrm{M}$ & 45 & $20 \mathrm{x}$ & $46^{\prime}$ & 493 & Small cell carcinoma & Small cell carcinoma \\
\hline 19 & $\mathrm{~F}$ & 74 & $10 \mathrm{x}$ & $10^{\prime}$ & 118 & AD metastatic & AD metastatic \\
\hline 20 & M & 51 & $10 \mathrm{x}$ & $\begin{array}{c}12^{\prime} \\
4^{\prime} 30^{\prime \prime}\end{array}$ & $\begin{array}{l}147 \\
54\end{array}$ & $\begin{array}{l}\text { Squamous cell ca with } \\
\text { Aspergillosis }\end{array}$ & $\begin{array}{l}\text { Squamous cell ca with } \\
\text { Aspergillosis }\end{array}$ \\
\hline
\end{tabular}

with proper lighting at a click of a mouse. The section can be easily viewed, annotated and documented. Accessibility of web-based VS allows to any pathologist to contribute in teleconsultation or education. Although the initial cost of equipment and software for creating and delivering VS is quite high, we think that this new technology has the potential to revolutionize the way the pathologists work and teach.

In our pilot study we conclude that Virtual Slide technology has adequately met the diagnostic objectives. It can not yet replace traditional way of routine pathology reporting but it may assure consultation requirements of hospital division. It allows producing high quality images easy assesses through the Internet, which may help in the specialization in pathology, facilitate quality assurance and be a source of educational programs.

\section{References}

[ 1] Brauchli K, Oberli H, Hurwitz N et al. Diagnostic telepathology: long-term experience of a single institution. Virchows Arch. 2004;444:403-409.

[2] Dee FR, Lehman JM, Consoer D, Leaven T, Cohen MB. Implementation of Virtual Microscope slides in the annual pathobiology of cancer workshop laboratory. Hum Pathol. 2003;34:430-436.

[3] Rojo MG, Pans JG, Pecesc BG, Bozec CD. Integrated solutions based on emerging standards for Digital Pathołogy in clinical practice. Update in Pathołogy. 21st European 
Congress of Pathology (8-13 Sept 2007, Istanbul Turkey), 2007:356-357.

[ 4] Glatz-Krieger K, Glatz D, Mihatsch MJ. Virtual slides: highquality demand, physical limitations, and affordability. Hum Pathol. 2003;34:968-974.

[ 5] Glatz-Krieger K, Glatz D, Mihatsch M. Virtual Microscopy http://vmic.unibas.ch. Path Res Pract. 2004;400:355.

[ 6] Burthem Jv Brereton M, Ardern J. et al. The use of digital virtual slides in the quality assessment of hematological morphology: results of a pilot exercise involving UKNEQAS(H) participations. Br J Haematol. 2005;130:293-296.

[ 7] Kayser K, Hufnagl P, Dietel M, Kayser G. From virtual slides to virtual pathołogy institution: the future of tissue-based diagnosis? Path Res Pract. 2004;400:355.

[ 8] Mireskandari M, Kayser G, Schrader T, Hufnagl P, Dietel M, Kayser K. Teleconsultation in diagnostic pathology. comparison of UICC-TPCC and iPATH servers using diagnosis-related scores. Path Res Pract. 2004;400:354.

[ 9] Molnar B, Berezi L, Diczhazy C et al. Digital slide and virtual microscopy based routine and telepathology evaluation of routine gastrointestinal biopsy specimens. J Clin Path. 2003; $56: 433-438$

[10] Schader T, Hentschel F, Mager AK et al. Currents studies in Virtual Microscopy. Update in Pathology. 21st European Congress of Pathology (8-13 Sept. 2007, Istanbul Turkey). 2007:356-357.
[11] Slodkowska J, Kayser K, Kus J, Auer I. Utility of the teleconsultations in the pulmonary pathology cases. Ann Academy Studenica. 2001;4:15-19.

[12] Slodkowska J, Siemiatkowska K, Wojciechowski M. Interactive telepathology with the Coolscope, in consultative diagnostics of the dispersed lung lesions. Virchows Arch. 2005; 447:389.

[13] Slodkowska J, Wojciechowski M, Siemiatkowska K. Telepathology in the consultations of lung diseases between two Polish provinces. Own experiences in applied various methods. (in press).

[14] Slodkowska J, Wojciechowski Z. The comparative assessment of the virtual slides quality created by various methods. 8th European Congress on Telepathology and 2nd International Congress on Virtual microscopy. Budapest, 2006. Abstracts, 63-SO.

[15] Woosley J. Creating interactive pathology tutorials in quicklime and flash. Hum Pathol. 2006;37:974-977.

[16] Scoville SA, Buskirk TD. Traditional and Virtual Microscopy compared experimentally in a classroom setting. Clin Anat. 20:000-000. http://www.interscience.wiley

Submitted:29 September, 2007 Accepted after reviews: 20 December, 2007 